\title{
National Transformation: Modern Reconstruction of a Unified Society
}

\author{
A Discussion About the Evolution Logic of Chinese Political \\ System
}

\author{
Shangli Lin ${ }^{1}$
}

Received: 5 November 2015/ Accepted: 17 December 2015/Published online: 1 March 2016

(C) Fudan University and Springer Science+Business Media Singapore 2016

\begin{abstract}
In the long river of time, the Chinese nation not only achieved its overall transformation from an ancient country, but also created a new model of development, which deserves to be called a great miracle in the history of human civilizations. The power creating this miracle came from both the development trend of human civilizations and Chinese people's creative transformation of their historical heritage. Specifically, it refers to how to fully transform from a traditional country to a modern country in terms of existing values, rules, and organizational systems, so as to achieve organic integration of the unification of the Chinese nation and the country under the rule of the people. Within the organic integration, China's internal development logic requires that modernization and democratization must be conducted under the premise of "keeping the unification of China", which is the historical requirement for China's modern transformation. The trend of modernization and democratization requires that national rejuvenation and unity must be based on people's democratic liberation as the engine, goal and mission, which is the realistic requirement for China's modern transformation. China's modern politics thus formed under the combined effects of historical forces, age forces, and human forces. Similar to all modern countries, China takes democratization as its fundamental orientation. However, its historical requirement, realistic foothold, and main force creating the modern politics are totally different from those of other countries. Therefore, China formed its unique modern politics and a republican and democratic form of modern politics with Chinese characteristics has been created. To grasp and understand China's modern politics, we should fully understand not only the nature of modern democracy, but also the source, foundation and process of China's modern politics.
\end{abstract}

Shangli Lin

sllin@fudan.edu.cn

1 Fudan University, Shanghai, China 
Keywords Unity $\cdot$ Democracy $\cdot$ National transformation

\section{Introduction}

China's modern politics did not come out of thin air. Instead, it is a result of repeated tentative explorations and practices. In the process, two historical trends played decisive roles: first, the people became the master of the country, i.e. the people's democracy; second, the unity and integrity of the country were maintained in the process of its modern transformation, which makes the ancient civilized country achieve the overall modern transformation. For a long time, people interpreted modern Chinese politics from the first historical trend, and therefore China's modern politics had to be closely related with revolution and democratic movements. In fact, this historical trend constituted the value orientation of China's modern politics, while the selection of the specific system of China's modern politics, as well as the resulting national form of organization were decided by the other historical trend-unity. "The Revolution of 1911 has helped the concept of democracy and republic win popular support ever since. It was publicly accepted that any remarks and actions in violation of this concept were illegitimate" (Liu 1981). Under this historical trend, what played a decisive role in the construction of China's modern politics was the strongest cultural belief and political mission in the hearts of Chinese people, which is maintaining a unified China and enabling the ancient country's transformation to a modern country with integrity in the modern transformation process. Unity is the axis of China; without it, China will lose the foundation and value of its existence as a whole.

\section{Traditional Unified Politics: Creation, Collapse and Historical Heritage}

In China's pre-modern history, unity, the way for the Chinese nation to survive and develop, and unified politics, which maintained the traditional state's imperial dictatorship, interlaced, decided and reinforced each other. Completely different from Western monarchy, China's traditional imperial authoritarian rule referred not to the eternal inheritance of imperial power through "ruling by one family over thousands of generations", but to the transverse succession of structural form of the national governance system centered by imperial power, the longitudinal connectivity of ruling power, and the extensive permeability of its value system. It can be said that China's traditional national unified politics was not a product of an emperor, a ruling class or a group, but a product gradually created by the premodern Chinese people based on their understanding and control of the world, nature, society, production and life. It resulted from both political domination and historical and cultural development. It was not created overnight. On the contrary, it was formed upon constant practices, explorations and historical selection in the process of historical development, containing both the ruler's personal will and the internal requirements resulting from Chinese history and culture. It is a kind of 
traditional political civilization and a part of Chinese civilization, and it created a unique Chinese traditional political scene: the inheritance of imperial power did not conform to "ruling the country by one family over thousands of generations", but "the Qin system was implemented for thousands of generations" in ancient China.

It can be seen that China's traditional unified politics embodies more the traditional state system and governance system than imperial rule. The state system and the governance system were the premise and foundation for the imperial power to realize their rule, and all of its legitimacy came from these systems. Therefore, "a state cannot survive without an emperor for even a day." Imperial power in any era, regardless of its majesty, would not shake the foundation of the state system and the governance system. What the supreme emperors in all dynasties could do was to adjust its internal parts and the power structure. This was not because imperial power was unable to shake the state system and the governance system, but because the emperors who hold imperial power worried that the unified political structure would be destabilized once the foundation was shaken, and therefore the state system, the governance system and the "unified" legitimacy granted by the underlying value of these systems would be lost, and even imperial rule itself would be endangered.

China's traditional national imperial rule was the "ruling the country by one family" ruling model, which was reflected in two aspects: first, the family who held imperial power controlled the country and imperial power was handed down within the family based on the patriarchal system; second, in a society with a hundred family surnames, every family had the right and opportunity to hold imperial power. Thus, each family could ask: "Do those gentry certainly have blue blood?" and express their aspiration of "I can replace him." Under the state system and the governance system, a family could not eternally monopolize the imperial power, which must be circulated among the public. The result was change of dynasties. The holding of imperial power was a result of fighting. To consolidate governance, any family who holds imperial power had to maintain the regime, the key to which did not lie in the power, but in the ability to win popular support. In addition to loyalty, the key to winning popular support was the ability to obtain the "legitimacy" of governance contained in the existing state system and governance system. With legitimacy, the ruler could not only effectively run the state system and the governance system, but also win popular support. Because of the unique political tradition and culture, the traditional state system and governance system operated depending on the monarch system, and could also surpass the monarch system, thus becoming the state system and the governance system maintaining the pattern of China's unity. By summarizing Ouyang Xiu's statement on legitimacy from the perspective of political science, Professor Bai Gang comprehensively presented the value of Chinese traditional political culture in this respect. The legitimacy of imperial power was not in dispute only in two cases: first, "the ruler is legitimate and has united the country together", such as the rulers like Yao, Shun and Yu, and the dynasties like Xia, Shang, Zhou, Qin, Han and Tang; second, "despite not being legitimate, the ruler could unite the country together after demise", such as the dynasties like Jin and Sui. The legitimacy of governance was controversial in another two cases: first, "there was not an emperor in the chaotic world, so stealing 
of power thrived and the legitimacy was ownerless", but the regime was "big and strong", such as the dynasties like Eastern Jin and Later Wei; second, "the ruler could not get legitimacy and failed to unite the country together", such as the dynasties like Wei and Five Dynasties (Bai 2008). Thus, we can see that the key for imperial power to be legitimate involves the following aspects: first, be legitimate; second, unite the country together. Achieving these two aspects means promoting the authority of the system for the pattern of unity as well as the governance system, and therefore achieving unity and peace in the country.

The fact that the state system and the governance system could exist as China's traditional political culture was because they originated from China's native history, culture and society. They were not only a product of political practices, but also a product of Chinese people's explorations and practices in the pre-modern era for maintenance of society, continuation of ethnic groups, organization of state, development of production, and support of people's livelihood. The symbol of China's unified politics was the Qin system established after the Qin State unified China. Neither the origin of the Qin system nor its final maturity took place in the Qin Dynasty. This was not only related with the short life of the Qin Dynasty but also related to the historical requirement for the generation of the Qin system. The reason is that a mature political system does not jump out of a ruler's head, it is the product of long-term historical explorations and practices, including its origin, developmental history, as well as post-formation improvement and maturation history. Thus, a long development period and various historical opportunities are needed. In the pre-modern era, this political system which developed independently needed a longer time. From this point of view, China's unified politics should be dated back to the first dynasty in Chinese history-Xia Dynasty and matured in Tang Dynasty and Song Dynasty which enjoyed strong centralized power and national prosperity, covering nearly 3000 years. If the establishment of the relatively perfect system of Zhou Dynasty in the pre-Qin period is deemed as the starting point, it covered nearly 2000 years. To sum up, China's traditional unified politics has formed through 1000 years of challenges and practices.

Prior to the appearance of political centralization centered by the imperial power in the Qin Dynasty, the pre-Qin system had experienced the royalty political era characterized by "collective master" and the monarchy era established based on blood and patriarchal system. Three major results were achieved in these two eras (Xu 1994) ${ }^{1}$ : the formation of a country as the Chinese nation, the establishment of the feudal system for the building of an enfeoffment-based national community with "family clan" as a unit, and the establishment of the etiquette system in line with patriarchal society, aiming to "govern the country, stabilize the state, keep the people orderly, and benefit future generations". ${ }^{2}$ Since these three achievements were embodied in the Zhou Dynasty, they are often considered as the specific content and representation of "Zhou system", which was eventually replaced by the "Qin

\footnotetext{
${ }^{1}$ Mr. Xu Zhuoyun made an analysis on the Western Zhou Dynasty's achievements in such three fields in his book History of Western Zhou, in which he systematically illustrated how the political creators in the Pre-Qin period made political civilization achievements in these three fields.

${ }^{2}$ Commentary of Zuo: The 11-YearHIstory of Yin Gong's Reign.
} 
system". The "Qin system" was established by replacing the "system of enfeoffment" with the "system of prefectures and counties", replacing the "aristocracy" with the "bureaucracy", and terminating feudal separatism by centralization of authority based on "carriage wheels all have the same standard form and size; all writing is written with the same characters". However, the emergence of the Qin system did not reduce the function and influence of "Zhou system" on the development of traditional Chinese political civilization. Therefore, the etiquette system which was created in the Xia Dynasty and came to maturity in the Zhou Dynasty was the foundation of China's operation, governance, and traditional state support system. In Confucius' theory on etiquette, its importance was clearly stated. Etiquette thus became the basis of governance and law that every ruler must follow and value. Confucius said: "It was by etiquette that the ancient kings sought to represent the ways of Heaven, and to regulate the feelings of men. Therefore, he who neglects or violates them may be (spoken of) dead, and he who observes them, be alive. It is said in the Book of Poetry, "Look at a rat-how small its limbs and fine! Then mark the course that scorns the proper line. Propriety's neglect may well provoke; A wish the man would quickly court death's stroke." Therefore etiquette is rooted in heaven, has its correspondence in earth, and is applicable to spiritual beings. It extends to funeral rites, sacrifices, archery, chariot-driving, capping, marriage, audiences, and friendly missions. Thus the sages made known the etiquette, and it became possible for the kingdom, with its states and clans, to reach its correct condition". 3 Since the etiquette system has fully embedded in China's cultural practices, social organizations and state governance and coordinated relationships among people, between man and nature, man and society, man and state, man and the world, and man and spirits in a comprehensive manner, it "not only constitutes the basic ethics, organizational structure and code of conduct in China's patriarchal society, but also establishes the tradition of Chinese culture" (Ge 1998).

The Zhou system incubated the Zhou Dynasty. The regime of Zhou Dynasty was established on the basis of patriarchal system and was a product of the combination of imperial power and clan power based on blood and clan. Under the patriarchal system, clan power came from the status of the clan and the size of the land ruled by the clan. As a result, promoting clans to rule the country by means of enfeoffment and balancing power order and relations of power within clans became the inevitable system option based on the combination of regime and clan power under the Zhou system. But this system was not only a system for a clan to rule the country, but also a system for a clan to split the country. It was based on the natural differentiation and separation of the clan's internal power, while the regime of the Zhou dynasty with the clan power system as its legitimacy basis was powerless to resolve the contradictions therein. The only way was to change the mechanism of ruling the country and the power allocation mode (Wang 2004). Thus, when the dukes ruled the territory of the Zhou Dynasty separately, on the one hand, they followed the Zhou system to ensure the legitimacy of their ruling; on the other hand, they started to abandon the way the Zhou system ruled the country and explored new systems, which was replacing the system of enfeoffment with the system of

\footnotetext{
3 The Conveyance of Rites. The Book of Rites.
} 
prefectures and counties. And officials were sent to govern new territories. The enfeoffment given to clans was reduced step by step, thereby weakening the leading role of blood relationship and patriarchal system in state authorities and national governance. These are the important historical and social foundations for the practice and development of the Qin system which unified the whole country thereafter. Without a doubt, the Qin system was created by the State of Qin, but its formation and development were achieved through the practice of political reforms and regime constructions of various kingdoms for uniting the country in the Warring States era. And the State of Qin created the core of the Qin system-system of prefectures and counties based on its imitation of the system of prefectures and counties of the State of Three Jins (Yang 2003). Therefore, in a certain sense, the Qin system is a new system created in the development of Chinese civilization. Because of this system, the State of Qin united the country and deepened and consolidated its ruling, hence we call it "Qin system".

The Qin system had the same mission with the Zhou system: to unite the country. But their orientations were completely different. The Zhou system was established on the logic of clan power while the Qin system was on the logic of regime. Accordingly, the force promoting the growth of the Zhou system was etiquette system and its result-aristocratic power, while that of the Qin system was Legalism- thoughts and officials who can help the emperor to rule the country. Therefore, compared with the Zhou system, the Qin system was undoubtedly revolutionary. This tells us that the process of establishing the Qin system was not only a system replacement, but also a replacement of power structure from the emperor-aristocracy pattern to emperor-officials pattern. This process eventually completed in the course of Qin's unification of China and the establishment of imperial rule. As the governance manner of the Zhou system had its inherent contradictions, so did that of the Qin system. The contradictions of the former led to feudal separatism in space while those of the latter led to the change of dynasties in time.

According to Marx, ruling the country by one family was a necessity of the development of eastern societies, because they were based on rural family communes transformed from incompletely disintegrated tribal societies to establish countries. Hence, unlike the regimes in ancient Greece established on the basis of class rule which was formed after complete disintegration of tribal societies, the regimes in eastern societies were established on the basis of clan governance. This showed that the social nature and basic structure that the Qin system and the Zhou system relied on are the same-patriarchal society. What is different is that the Zhou system directly promoted the patriarchal system of patriarchal society as the institutional foundation of state power's construction; and thus combined regime and clan power together. The Qin system did not negate patriarchal society and patriarchal system, otherwise, it was impossible to establish hereditary monarchy. But the regime construction of Qin system was largely beyond patriarchal society and patriarchal system. The most obvious evidence was that except for the emperor, the country was not ruled by a clan, but by talents, which made the social status of a clan could not be directly converted to power status in national governance. In this way, aristocrats and aristocracy resulted from the feudal system were gradually 
replaced by bureaucracy established on the national governance manner by relying on talents. The Qin system established a more united and firm pattern of hereditary monarchy than the Zhou system by relying on such a system. And the Qin system created high degree of centralization system and its corresponding mighty imperial power, but from the very day of its establishment, it made Qin Shi Huang's pursue of "ruling the country by one family over thousands of generations" just a beautiful dream during his process of uniting China by using the Qin system. Because when the Qin system substituted aristocracy with bureaucracy, the social basis for the existence of "ruling the country by one family over thousands of generations" had lost, which was aristocratic society. Because of this inherent contradiction of hereditary monarchy, state power can be held by a clan, but could not always be the same clan. Once the ownership and mastery of state power lost the sanctity of blood and clan relationship, state power would naturally become a public resource of the whole society. In a patriarchal society with clan as unit, each family or clan had the right to involve in. State power held by different clans formed different dynasties. Therefore, the change of dynasties became the pattern of hereditary monarchy of Qin system, which was in stark contrast with that of the Zhou-system characterized with enfeoffment and feudal separatism.

After uniting China, Qin Shi Huang established the centralized system with imperial rule as the core and the system of prefectures and counties and bureaucracy as the backbone, and attempted to create hereditary monarchy of "ruling the country by one family over thousands of generations" by this regime system. However, the Qin Dynasty "collapsed after two generations". Later, Han Dynasty adopted Qin system and thereafter, Qin system lasted in China for nearly 2000 years. According to Jia Yi's summary on the lessons of the Qin dynasty's collapse after two generations, the reason for Qin's early death did not lie in the Qin system, but in the administration of the Qin dynasty. Jia Yi said "The status of offend and defend will be changed if the emperor did not implement benevolent policies." As a result, the Qin Dynasty which had once united the whole country was destroyed by an ordinary man Chen She. Obviously, it was tyranny rather than Qin system that caused Qin's collapse. Although Qin's tyranny had something in line with Qin system, it was more directly related to Qin Shi Huang's governance "without benevolence". On the one hand, the situation of "absence of benevolence" was caused due to the objective political situation that Qin needed to establish and consolidate the new system of centralization by using political power, eliminate resistance from the remaining forces of conquered six kingdoms, and defend its frontier that had expanded greatly; on the other hand, it related to the governance philosophy of Legalists' thoughts that was adhered to in the course of uniting the whole country under the Qin system. And the role of "law, tactics, and authority" in consolidating power and governing the country was over emphasized. Because of this, the Han Dynasty, Qin's successor, inherited Qin system, but adopted the "Philosophy of Huang-Lao School" rather than Legalists' thoughts to govern the country, heading to the other extreme. With an emphasis on etiquette, governance without too much interference, recovery and rehabilitation of people, it created "Rule of Wen and Jing" at the beginning of the Han dynasty. In the process, the Qin system that Han inherited 
consciously integrated Zhou system's etiquette system and its thoughts and principles.

Though there are original religions in China, the main intellectual support that emperors need to govern the country did not come from religious power, but from intellectuals mastering the "philosophy" of the country, because in China, secular power was arranged by the natural law, and human relations and secular life were arranged by patriarchal system and ethics. To rule the country, the emperor must effectively combine his "power" and the "philosophy" mastered by the intellectuals. This ruling form flourished in the Spring and Autumn period and Warring States Period and then existed as a political form throughout the whole of traditional Chinese politics. Its mechanism was the same as what Marx emphasized, that a system and its governance must have corresponding ideological support. Meanwhile, it was consistent with the principle that Weber emphasized: modern politics must be established on the effective integration of "instrumental reason" and "value reason". From this perspective, in order to consolidate the Qin system, a problem must be solved: laying an ideological foundation to obtain full value rationality. To this end, Qin Shi Huang turned to the Philosophy of Legalist School, while the early Han dynasty adopted the Philosophy of Huang-Lao School. The two philosophies were not designed to pay close attention to the conditions, feelings and livelihood of the people, but emperors' ruling policies. Therefore, these two choices were made for the purpose of governing and consolidating political power rather than helping the Qin system win public support and blend in tradition in society. This objectively led to Emperor Wu of Han's third historical attempt, i.e. accepting Dong Zhongshu's advice of "Domination of Confucianism" and adopting the ideological system centered by Confucianism for the Qin system. Compared with the Philosophy of Legalist School and Philosophy of Huang-Lao School, this ideological system was based on the Chinese patriarchal society in which ethics was the center. And this system combined the ethical principle of patriarchal society and the governing principle needed by the hereditary monarchy of imperial rule together to achieve mutual connection and coordination, thereby creating an ideological operating system which stemmed from human nature, developed by public support, took root in society, and implemented in the whole country, and creating the unified political domination characterized by pursuing cultivation of oneself, put family in order, govern the country and bring peace to the world. In such unified politics, the "power" of imperial authority did not come from the imperial authority itself, but from the "system" that supported the imperial authority and the underlying "philosophy". The actual operator of the Qin system was officials. In the unified political pattern where world peace depended on the coordination of "power", "system" and "philosophy", the selection and management of officials became the key to the rise and fall of a dynasty. Because of this, after inheriting the Qin system, except selecting an appropriate ideological system for it, the Han Dynasty also tried to create an official selection system that was essential for the operation of the Qin system and attempted to achieve effective coordination of the two systems.

Both the Qin system and the Zhou system had established a corresponding bureaucratic system. Rites of Zhou which directly revealed the Zhou system was a book describing governance plans through the bureaucratic system, which 
established the Chinese political tradition that the bureaucratic system was used to represent institutional systems, national organizations and forms of governance. Due to this tradition, a country could not survive without an emperor. Accordingly, the emperor could not rule without officials. The combination of an emperor and officials was the basis for a stable governance and peaceful country. The difference was that, in the Zhou system, the officials under the level of emperor and duke were hereditary, called hereditary ministers. In the Spring and Autumn period and Warring States period, with the rise of intellectuals, the hereditary system was shaken, and promoting those who were capable thus became a recognized way for state governance. The principle of conferring officials based on military exploit established during Qin's unification of China fundamentally destroyed Zhou's hereditary system, and ushered the official selection system. After Han inherited the Qin system, in the first year of Yuanguang Era (134 BC), Emperor Wu launched an annual activity - to recommend one filial and one incorrupt candidate, thus official selection became an institutional arrangement. Therefore, some scholars believe that this initiative laid the foundation for China's millennium-old official selection system (He 1998). Since then, the improvement and development of the official selection system has become an important part of the improvement and development of the Qin system as well as the key for the perfection and effectiveness of the Qin system. To some extent, the symbol of China's maturity was not the consolidation degree of imperial power in the system, but the systematic level, institutionalized level, and standardized level of the official selection system. Therefore, we could say that the establishment of the imperial examination system in the Sui and Tang dynasties not only marked the final decision on the standard and systematic imperial examination system after the recommendatory system in the Han Dynasty and the ninth-rank system in the period of Wei, Jin, Northern and Southern Dynasties, but also symbolized the most mature and perfect form of the Qin system that the operation of traditional unified politics relied on. The prosperity of the Tang Dynasty was achieved on the basis of such a perfect system.

This shows that the Chinese traditional unified political form was not shaped in a day. It was the result of thousands of years of growth and evolution. Originating from traditional Chinese society, getting nourishment from China's cultural wisdom, and developing in China's changing history, the Chinese traditional unified political form conformed to the existence and development of the Chinese nation's unity in terms of form, and coincided with Chinese traditional hereditary monarchy in terms of function, and hence closely integrated society and state. Besides, it effectively supported the organization and operation of the enlarged traditional large-scale national system. Five characteristics can be discovered upon careful examination:

First, it is institutional. One of the reasons for the fact that "the Qin system was implemented for thousands of generations" in ancient China was that the Qin system was not only the institutional form of imperial rule, but also that of traditional state organization and governance. Thus, imperial power could be circulated among various families and clans, but all emperors, whoever he is, must take the Qin system as the standard for state governance and operate the Qin system. 
Second, it is deeply rooted. Originating from traditional Chinese society, the Qin system was inherently consistent with the patriarchal society. The most basic manifestation was that family and state had the same structure, and coordinated with each other. Because of this, the Qin system gradually rooted into everyone's life and heart, and therefore the entire national system became the basic platform and space for everyone to practice and make achievements. The way to express it is "cultivate oneself, put family in order, govern the country and bring peace to the world".

Third, it is open. This was mainly reflected in the fact that all powers in the Qin system were not exclusive, so they were fully open. Imperial power was not owned exclusively by a clan, and officials did not belong to a specific class forever. However, this openness was not formed on power's institutional arrangements, but on the non-aristocratic social structure. In other words, it was the result of inherent requirements of social form rather than the system design.

Fourth, it is precise. By studying various regimes and corresponding institutional forms created by human beings, we can find that there are mainly two keys to achieve systems' consolidation and improvement: the first is that the system is able to maintain a lasting interaction with the outside environment; the second is that the system has a strong function of self-healing and improvement. From this perspective, it is not difficult to find that the Qin system has both these two features. First, through the official selection system, the Qin system could not only effectively introduce its ideology into people's knowledge system and daily life, but also continuously selected talents who agree to the ideology and have the governance ability from society. Second, through the official selection system, the three systems supporting the national system, i.e. bureaucracy, ideology and patriarchal society, were effectively integrated into a mutual supported and mu tual shaped closed loop system. Finally, though the Qin system took imperial power as its core, because its legitimacy and rationality was based not to violate the country's basic institutional system, the imperial power can revise itself but the internal mechanism and basic structure of the Qin system must be respected. Therefore, compared to the personalized imperial power in different periods and different dynasties, the Qin system with historical universality had relative independence. Thus, the structure and operation of the Qin system had inherent precision and interconnectivity, both internally and externally. The change of any step would affect the entirety and its fundamental pillar.

Fifth, it is self-supportive. Neither the organization and operation of the Qin system as a whole nor the consolidation and implementation of imperial power were inseparable from the official selection system. It can be said that the official selection system was the axis of the traditional unified political system, and endowed it with unique self-sufficiency. This self-sufficiency was reflected as follows: the key to running the Qin system was the officials selected by the official selection system, while the key to selecting officials was the inherent official selection system derived from the Qin system. Therefore, self-sufficiency was formed among officials, the official selection system, and the Qin system as a whole. This self-sufficiency and openness were the premise of each other and jointly provided impetus and resources for the existence and development of the Qin system for thousands of years. 
The above five characteristics enabled the Qin system to obtain relative independence in the process of self-development and improvement, becoming the traditional state system with a high degree of historical and cultural legitimacy beyond stages of history and ruling forces. However, it was also because of these characteristics, especially self-sufficiency, that the more mature the Qin system became, the more inherent flexible space it lost. And the Qin system eventually became a system that was unable to ferment revolution. The self-sufficiency of the Qin system determined that the change of its basic structure would immediately interrupt its inherent complementary relationship and disable the whole system to function properly, and then would make the whole system impossible to interact and exchange with the outside community. The reason that the 2000 years of Qin system was destroyed by the Wuchang Uprising in 1911 breaking out a thousand miles away from the capital was not the destructive power of the uprising. More importantly, it was because that the previous New Policies of the late Qing dynasty had abandoned the core support of the Qin system, which was the reform of abolishment of the imperial examination system in 1905. Therefore, the Wuchang Uprising was no more than the last straw for the demise of the Qin system. In a sense, the Qin system ultimately disintegrated under both internal and external forces, and therefore lost the basis and possibility for recovery. The long history of the Qin system and its complete disintegration were both wonders in the development of human political civilization. However, the greater wonder appeared later was that the Chinese nation which has accompanied the Qin system for 2000 years did not split along with its complete disintegration. On the contrary, the Chinese nation still maintained as a whole country and was still capable of creating a brilliant history in great changes. On the one hand, the strength creating the greater wonder came from the Chinese nation's unified survival and development manner in thousands of years of historical development; on the other hand, it came from the mechanism and strength arising from the establishment of republic and democracy in China after the disintegration of the Qin system.

\section{Republic and Democracy: Modern Political Form of the Unified Society}

Chinese history and culture really did not have the basis and capacity to generate modern democracy, but the Chinese nation which had a history of autocratic politics longer than that of any other country thoroughly destroyed the traditional autocratic system which had operated for the longest time, and had the most perfect structure, and established a modern republican and democratic system. There was not evidence of reform at all in the new system, and it was established in the most revolutionary way. Therefore, in the face of modern Chinese politics, some people may ask: Why did not the Chinese nation with a long history of autocratic politics turn to constitutional monarchy at last while some European countries which had a short history of monarchy retained some elements of autocratic system in the thorough democratic revolution and embarked on the path of constitutional 
monarchy? The answer to this question can only be found in the unique historical logics of various countries' national modern transformation.

In a sense, to face this question is more important than to answer it. Because the real significance of this question is that it reveals such a historical development reality: though democratization is an inevitable pursuit of all countries, the key to their construction of democracy does not lie in the construction of a pure democratic system, but in the construction a modern national development system that enables the growth of democracy. Thus, for any country, its construction of democracy is not decided by general principles of democracy, but by the inherent logic of national development and transformation decided by its specific society, history and culture. Because of this, British democratization retained monarchy, while Chinese democratization broke with its traditional system, chose republic and democracy, and independently assembled a modern political system with Chinese characteristics by using modern political elements completely from the West.

For China, democratic politics was undoubtedly an alien political form, but modern China's embarking on the path of republic and democracy was an inherent requirement of its national transformation. This seemingly contradictory judgment is completely in line with China's reality. It is the historical heritage of the 2000 years of unified politics after its complete disintegration that had a strong inherent requirement for republic and democracy.

China's intention to replace the thousands of years of autocratic politics of the Qin-system with Western democracy started from the late 1850s and the early 1860 s (Xiong 1986). The direct reason was the national crisis caused by the invasion of Western Powers after the Opium War. In the face of a new era and a new world, for the first time, Chinese people realized that the 2000 years of Qin system was the source of national decline and started thinking of the possibility of reforming the old system or starting a revolution to change the old system, hence two completely different standpoints and plans represented respectively by the reformists and the revolutionaries appeared. The reformists advocated reforming the existing system, namely the millennium-old monarchy, and turning to constitutional monarchy, while the revolutionaries advocated destroying the millennium-old monarchy and establishing republic and democracy. The winners of this argument were the revolutionaries. It seemed that they won because their proposition was more in line with the times in terms of value and they had immediate revolutionary actions. However, in fact, the victory of the revolutionaries was not based on the thoroughness of their revolution and their construction of theories, but based on the complete failure of the reformists' theory on constitutional monarchy and their practices. This failure was actually not caused by the reform theory and practice, but the unchangeable nature of the 2000 years of Qin system. As mention above, the 2000 years of Qin system was destroyed by the new policies adopted to transform to constitutional monarchy in the late Qing Dynasty rather than the gunfire of the Wuchang Uprising in the Revolution of 1911, because any reform of the new policies was lethal for the highly institutionalized and precise Qin system. It can be said that the revolutionaries' victory over the reformists was more a product of the reformists' failure in the reformist practices than the result of the revolutionaries' revolutionary actions. 
In fact, the reformist practices concerning the 2000 years of Qin system and the traditional country it shaped began shortly after China's failure in the Opium War, and then experienced Westernization Movement, Taiping Heavenly Kingdom, and the New Polices of late Qing Dynasty. The social and political forces involved included traditional officials, traditional scholars in pursuit of fame, a great deal of farmers, local squires, and the last court powers. It can be said that all kinds of social and political forces in the traditional country have made efforts to reform based on their positions and roles in different ways, but they all failed. Either analyzed from the reform or the Qin system as the object of the reform, finds that the setbacks in the process of reform and the ultimate failure were both a necessity of history and a necessity of the system. Namely, the unchangeable nature of the Qin system would definitely cause the failure of the reform. Therefore, the ultimate failure of reform did not mean unable to realize the target, but indicates the complete disintegration of the system which it intended to reform. The success of revolution against the failed reform was not thorough. Thus, after the failure of reform, China was bound to enter into a historical period to conduct revolution thoroughly and achieve the ultimate success. The strength and mechanism driving China onto this historical track were the significant historical heritages brought by the collapse of the 2000 years of autocratic monarchy: republic and democracy.

Although republic and democracy were not generated in China, they were the only political choice for China to achieve modernization. This was decided not only by the times of China's modern development, but also by the historical heritages left by the thorough collapse of the 2000 years of autocratic monarchy. Specifically, there were three major historical heritages:

Firstly, the collapse of the 2000 years of autocratic monarchy did not only mean the end of a dynasty and a system, more importantly, it meant the thorough disintegration of the traditional unified politics which maintained the survival and development of the unified Chinese nation. The unified politics integrated people's political life and social life, people's belief system and national institutional system, as well as individuals, families, society, and state together. Therefore, its thorough disintegration meant the disintegration of the value system, institutional system and organizational system which maintained the whole society, state, and nation. While declaring the possible danger of the state and society's disintegration, this disintegration also announced that China lost the ability and basis to restore monarchy. Due to the objective reality that it was impossible to rebuild the traditional monarchy to maintain the survival and development manner of the unified Chinese nation and achieve large-scale internal integration, the Chinese nation should quickly establish a modern institutional system which can complete this mission in the course of transformation. Therefore, the disintegration of monarchy brought two distinct historical regulations for China's modern transformation: first, China could never return to monarchy; second, in the course of modern transformation, China must choose and establish a modern institutional system for the purpose of maintaining the survival and development of the unified Chinese nation.

Secondly, among modern political systems, the new modern institutional system could either be republic and democracy or a modern autocratic system, such as 
military tyranny. It seems that because of the failure of Yuan Shih-kai's military regime, China finally choose republic and democracy. But fundamentally, it was the Chinese traditional social structure and ideology shaped by the traditional monarchy that caused China's final decision. It covered two aspects. First, China's traditional monarchy was a civil regime. Although the army was inseparable, soldiers were never the core of politics and their development could not go beyond the existing institutional framework and arrangements. The "new army" under the leadership of Yuan Shih-kai was built under the old system. Only when compared with traditional Chinese army, it was new. However, it was not actually a modern army. Second, Chinese traditional monarchy's political relations and arrangements of political order were established under the principle of "people are the foundation of the state". Therefore, the state's core political relations and political order were basically constructed with "the people" as a party, such as people's relationships with the emperor, officials and the country. Because of these relationships, once the monarchy collapsed, "the people" would naturally become the main force in reality after the disappearance of the emperor, officials and the state established by monarchy. This change exactly coincided with the inherent tendency of modern democracy. It can be seen that, after the collapse of monarchy, China's modern transformation to republic and democracy had a natural social foundation which was laid by the traditional monarchy.

Finally, traditional Chinese social structure determined that after the collapse of the millennium-old monarchy, the people who were mainly laborers became the main force of Chinese society and play an inherent decisive role in the choice and establishment of China's republic and democracy. According to Marx, Chinese traditional society was a product of Asian social development. The state was not established on the basis of the social structure that society was fully divided into classes, but on the concentration of rural communes, which was traditionally called "a state upon concentration of families" in China. This showed that traditional Chinese society was not a typical society with a class structure. It was more like the "occupation division" society as Liang Shuming said, i.e. a society in which the basic structure and order are formed based on political job placement in the order of "scholar, farmer, artisan and merchant" (Liang 1990). State power was held by the officials formed by the elites of such four occupations after passing the imperial examination. Then the entire society was divided into two groups: the group of officials and the group of scholars, farmers, artisans and merchants. People in the two groups could move to the other group, and communicate with each other. So, Mr. Chen Xulu, a famous modern historian, used the concepts of upper society, middle society, and lower society respectively to explain modern China and analyze its inherent complexity and fluidity (Chen 1992). The upper society and lower society respectively refer to the group of officials and the group of scholars, farmers, artisans and merchants, while the so-called middle society refers to the people rising from the group of scholars, farmers, artisans and merchants to the group of officials, and its core members are scholars who remained unchanged. So, the group which disintegrated together with the thorough collapse of the monarchy system must be the traditional group of officials. Accordingly, the group of scholars, farmers, artisans and merchants would surely become the decider of society and state, and 
therefore theoretically, state power would return to the hands of people who take the occupational group as structure. Such social restructuring and transfer of power would inevitably require the new political system to be a democratic political system with the people as the subject.

The foregoing three major historical heritages showed that in order to transform to a modern nation, China must reconstruct its national organizational and operating system. And what is most important is to reconstruct its political system in all respects. Unable to return to the past, reconstruction must orient toward modernization. As stated above, there were two basic choices for system reconstruction: first, autocratic system, such as various types of military tyranny and tyranny of privileged class in Germany, Japan, South Korea and Latin American countries; second, democratic system. To maintain the millennium-old unified Chinese society, the two options were both feasible and could meet the real needs. Objectively speaking, the selection and practice of modern system after the Revolution of 1911 were trapped into the dilemma between military tyranny and republic and democracy (Qi 2010). ${ }^{4}$ Actually, Yuan Shih-kai was military tyranny, but his military tyranny intended to return to the past and eventually ended in failure, and therefore caused the country descend into the state of warlordism. The historical background ultimately reflected the historical inevitability and urgency for China to choose republic and democracy. Under this historical background, we can see that Yuan Shih-kai's failure and the ensuing short-lived warlord system were both directly related to the traditional unified politics and the historical heritages left by it. As for Yuan Shih-kai, he did not fail because of his military and political power, but because of the realistic requirement left by the disintegration of the traditional unified politics. Namely, monarchy could not be recovered in China. Li Jiannong clearly stated that the attempt to recover monarchy was the key reason for the failure of Yuan $^{5}$ (Li 2002). As for the short-lived warlord system, Professor Qi Xisheng said: "The most important thing was the common belief that China must be finally unified. As a result of this belief, these warlords realized that their reign would be short, and therefore they had an inherent sense of insecurity. No one of them expected to maintain the current situation forever" (Qi 2010). So far, the historical requirement for China's transformation to a modern nation which derived from the traditional unified politics and its historical heritages has been clear: the combination of democracy and unity.

\footnotetext{
${ }^{4}$ There were at least four constitutional laws in between 1911 and 1924 . The political system constantly changed in the order of monarchy, republicanism, regent system, etc.

5 "If Yuan Shih-kai had dropped his pipe dream to be an emperor, the crack within the Northern Warlords would not have happened immediately. Namely, although the progressives hated Yuan, they wouldn't go against Yuan together with the Kuominists. As we know, when Yuan promoted reform in the provisional constitution, the leaders of the progressives were still obedient to him and hoped him to implement the so-called enlightened despotism to save China. Unexpectedly, Yuan desired for 'absolutism' and 'monarchy' rather than 'openness' and 'absolutism.' Since 'absolutism' was unlikely to be 'openness' and 'monarchy' was promoted, the leaders of the progressives titled steady forces in support of Yuan had to fight against Yuan. Since then, disputes occurred among the Northern Warlords. Therefore, the monarchy movement was not only a big crisis for the Republic of China, but also a key factor for the ups and downs of the Northern Warlords."
} 
So, China's choice of republic and democracy in the course of transformation to a modern nation was a decision to comply with the world trend, but more importantly, it was a choice based on its historical requirement and demands for realistic development. Thus, China's choice of democracy did not start from its ultimate value and typical pattern, but from the purpose of maintaining national internal unity and the overall restructuring. Specifically, it was how to achieve the overall modern transformation of the millennium-old ancient country under the premise of maintaining China's unity, how to establish a democratic modern state system and develop modernization. Building a modern nation in this way was undoubtedly unprecedented. From the beginning, China strived to combine the construction of democracy and the internal unity of a big power which maintained pluralistic unity with the effort to achieve rule by the people, i.e. governance by the majority of the people. Therefore, China firmly chose republic and democracy, making "republic" the fundamental principle to construct a modern democracy in China.

"Democracy" and "republic" are two different words both in Chinese and in English. American political scientist Robert Dahl believed that these two words refer to the same form of government-democratically elected government (Robert 1999). The word "democracy" comes from ancient Greek based on their democratic practice while the word "republic" comes from Rome based on the democratic practice of Roman Republic. In fact, when deciding the title of the state, the Communist Party of China also believed that "democracy" and "republic" had the same meaning. Thus, they chose "the People's Republic" rather than "the People's Democratic Republic". The question is that now that "democracy" and "republic" have the same meaning, why choose "democracy" rather than "republic"? Zhou Enlai gave an explanation from two dimensions: first, the "people" here means the people's democracy, a direct embodiment of "democracy"; second, "it is better to use "republic" to refer to a country. After the Revolution of 1911, China's state name is the 'Republic of China', containing the meaning of republic, but not completely. There are two ways to explain it, which is puzzling" (Zhou 1984). This analysis confirms once again that China's construction of modern democracy has always started from two perspectives: rule by the people and national unity. "Republic" is undoubtedly the most appropriate expression of political discourse and institutional form for national unity.

According to Robert Dahl, "democracy" and "republic" both represent democratically elected governments and stress citizens' equal participation in public affairs, election of representatives, and organization of government. But analyze either from the historical source of the two words or the democratic practice represented by these two words, we can find that their standpoint or focus is different. The former focuses on people's liberty and political participation, while the latter stressed that state power belongs to the people and it is public. Although the two standpoints and focuses are two essential aspects for the democratic principle and practice, the former focuses more on the sanctity of civil liberty while the latter focuses more on the public feature of state power. Based on the construction of democracy and practice of development, for a state without democratic tradition and foundation, or for a state whose civil society is not developed in today's Western theory, establishing the principle of republic and 
developing democratic politics based on the public feature of state power, i.e. state power has changed from "private resource" to "public resource", is undoubtedly a more viable option for democratic development. The standpoint and focus of construction of democracy from the perspective of "republic" are naturally public features of state power. Therefore, Sun Yat-sen took the ideology of "the world belongs to the people" that Confucius proposed 2000 years ago as the core principle of China's democratic construction (Sun 1996). ${ }^{6}$ He stressed that only adhering to the principle of "the world belongs to the people" to set the state power could achieve the republic of the Chinese nation, build a civil government under the control of the civilians, and create a society of the people, by the people, for the people". The history of China's national modern transformation showed that the republican practice of adhering to the principle "the world belongs to the people" not only maintained the unity of Chinese nation and modern integration of the millennium-old ancient country, but also achieved the form of democratic politics characterized by people as masters of the country.

\section{National Overall Transformation: The Millennium-Old Ancient Country Heading to Modern Republic and Democracy}

As an inevitable phenomenon in the modernization of all countries, transformation, together with modernization, appears not only at the social level, but also at the national level. Originating either from society or from the state, the transformation brought about by modernization would go beyond itself and spread to another level, so the two levels of transformation are often mixed as a whole. And "social transformation" or "national transformation" is used to summarize. Karl Polanyi studied the transformation at the social level. Although he touched upon social transformation and national transformation at the same time, nevertheless, in order to understand the transformation and change brought about by modernization from the perspective of grand time and space of development of human civilization, he went beyond the specific state and its corresponding society and understood from the change of an era and the transformation of a social system. Because of this, he used a macroscopic concept_-great transformation (Karl 2007). However, when a specific country became the focus, Polanyi's analysis on "great transformation" could only become a background factor for the exploration of a specific country's transformation. If we analyze according to this background factor, we can only grasp the situation and degree of transformation, while the inherent logic of transformation of a specific country and its strategic objectives and selection of strategies are difficult to grasp. Therefore, in order to grasp the specific transformation brought about by national modernization, we should start from the internal relations between the two levels of social transformation and national transformation.

\footnotetext{
${ }^{6}$ By virtue of Confucius's ideology that "the philosophy for state governance is the ideology that the world is shared by all people," Sun Yat-sen expressed his ideology that the modern Chinese nation should develop from "household governance" to "the whole world as one community." To be specific, "the world should be a community shared by all people. See Sun, Yat-sen 1996.
} 
With regards to transformation, Marxist theory on the relationship between economic base and superstructure is the most profound and logical. Marx separated national transformation as a superstructure from social transformation with an economic foundation as its main part and believed that the impetus for social transformation derived from the development of production. He said: "The mode of production of material life conditions the social, political and intellectual life process in general." "At a certain stage of development, the material productive forces of society come in conflict with the existing relations of production, or with the property relations within which they had been at work hitherto. From forms of development of the productive forces, these relations turn into their fetters. Then an epoch of social revolution begins. With the change of the economic foundation the entire immense superstructure is more or less rapidly transformed. In consideration of such transformations, distinction should always be made between the material transformation of the economic conditions of production which can be determined with the precision of natural science, and the legal, political, religious, aesthetic or philosophic-in short, ideological forms in which men become conscious of this conflict and fight it out" (Karl 1995). According to this theory, Marx believed that national transformation was in fact conducted in the interactive process of social revolution, political revolution and cultural revolution caused by the production development. The production development is the base, while social revolution, political revolution and cultural revolution are the path and implementation model of national transformation. As for how social revolution, political revolution and cultural revolution are conducted in the specific transformation, Marx defined the two-way interaction among three revolutions when distinguishing the two transformations. First, the transformation triggered by the production-based economic conditions is material and can be pointed out with the precision of natural science. Thus, people can speculate the possible economic, social and political transformations based on their grasp of the quantity and quality of production development. Second, based on the subjective response to the conflicts in reality, people consciously generate political thoughts, spirits, and concepts, i.e. the active transformation of the superstructure. Marx considered the latter as an "ideological form". Accordingly, we can consider the former as a "form of production pattern". Thus, we can summarize the theoretical logic of national transformation deduced from Marxist theory as: "three revolutions and two forms". Using this theory to examine the modern transformation of different countries, we can find that the relationship and inherent logic between the three revolutions and two forms are completely different in different circumstances of different countries, thus forming different paths and forms of national transformation, as well as different development strategies and development forms after the transformation. In the Western modern national transformation, "three revolutions and two forms" were generally mixed as a whole. Namely, social revolution, political revolution and cultural revolution interacted with each other and promoted each other. Accordingly, the two forms of transformation developed together and supported each other. China was completely different in this regard.

For the ancient Chinese nation, the fundamental driving force promoting its transformation to a modern country was also production development, but it was not 
its own production development, but that of Western society. Thus, the production development did not promote its national transformation internally, but externally. This was represented by the intense impact on the old imperial system caused by the new economic forces, new market forces, and new underlying political forces, which tried to make it in line with the requirements of external forces. Therefore, such impact was coercive and even destructive. Under such circumstances, China's national transformation could not wait for its internal economic development and production development as Western countries do. Instead, its transformation must be conducted in "the legal, political, religious, aesthetic or philosophic forms in which men become conscious of this conflict and fight it out". Thus, this transformation was not conducted based on precise motives generated by production development and clear transformation logic. Instead, it was promoted based on the main power's understanding of the nature of this conflict and the establishment of national and social wills used to overcome the conflict. In the face of strong external conflicts, in order to maintain the survival of the community and achieve selfpreservation, the reforms that China's national transformation required would naturally first start from maintaining the existing political system and the great unified community. The reforms that China underwent after the Opium War were all carried out based on these two basic points. When it was completely hopeless to maintain the existing traditional political system, maintaining the existence of great unified national community became the fundamental standpoint for national transformation. Accordingly, the problem that should be addressed for the reform changed from how to maintain the unified community by maintaining the existing political system into how to maintain the unified community by establishing a new political system.

It can be seen that China's national transformation started from the superstructure. Since it faced the pressure and impact on the whole community from external forces rather than the impact on the internal structure of the community from internal production forces, the standpoint of its transformation remained the same:, i.e. prevented external forces from destroying the unified community, and therefore enabled it to existence in the process of modernization. This is fully demonstrated in the thoughts and proposition of "keeping the unification of China" of Kang Youwei and Liang Qichao who promoted the Hundred Days' Reform. Although they often swung between "keeping the unification of China" and "saving the emperor", their fundamental standpoint was actually the former. The latter was merely a strategy or a method to achieve the former. ${ }^{7}$ Kang Youwei, who was much more conservative than Liang Qichao, gave top priority to keeping the unification of China: "Reading his works, we can find that his main concern was to save China through reform and his defense for Qing dynasty was to make way for reform. He did not oppose saving the Qing dynasty for the sake of saving China. However, if the defense of Qing dynasty became an obstacle of modernization, namely, if it was impossible to change autocratic monarchy to constitutional monarchy in a peaceful and orderly

\footnotetext{
${ }^{7}$ In 1899, in order to avoid the situation that China would be beset with troubles internally and externally and might fall apart at any time, Liang Qichao published the article "Necessity to Keep China Intact by Blaming the Chinese Emperor".
} 
manner, he would rather abandon the Qing dynasty" (Xiao 1997). It can be seen that, in the process of China's promotion to the national transformation, there could be different opinions, ideas and actions for updating of ideology, selection of form of government, practice of political reform, and mobilization for revolution, but the national will behind it and the core mission that it decided were "keeping the unification of China". Thus, during the national transformation, "keeping the unification of China" was the purpose, while the others were nothing but methods.

Concerning modern Chinese history and social development, "keeping the unification of China" had three internal requirements: keep the existence of the state; keep the integrity of the Chinese nation; and keep the unity of the whole country. This determined that the national transformation with "keeping the unification of China" as the axis was not a transformation that just took modernization or democracy themselves as purposes, but a transformation for the sake of effective combination of the maintaining of national internal integrity and the promotion of modernization. Otherwise, the country might be abandoned by the modernization trend and the whole world, just like what Sun Yat-sen said: "The global trend goes ahead. Those who bow before it survive and those who resist perish". Because of this, the selection of system during the national transformation should consider not only its modernity, but also its integrity. Besides, the possibility of undertaking political revolutions and social revolutions should also be considered. This is the real reason why the reforms and revolutions in modern China have long swayed between constitutional monarchy and republic and democracy. The key for the failure of constitutional monarchy was that it could not achieve its proper modern transformation, which mainly resulted from the inherent characteristics of China's millennium-old monarchy. The failure of constitutional monarchy revealed the necessities for the success of republic and democracy from an opposite perspective: preserve the modern integration of China as a unified community in the course of providing a political system for China's modernization, and therefore achieve the overall transformation of the millennium-old ancient country to a modern country.

\section{References}

Bai, Gang. 2008. Chinese Emperors. Social Sciences Academic Press, 522.

Chen, Xulu. 1992. The Evolution of Modern Chinese Society. Shanghai People's Publishing House. 257-276.

Ge, Zhaoguang. 1998. Chinese Ideological History, Volume I. Fudan University Press, 108.

He, Huaiyuan. 1998. Electoral Society and its End. SDX Joint Publishing Company, 90.

Karl, Marx. 1995. Preface of the critique of political economy. Selected Works of Marx and Engels, Volume II. People's Publishing House, 32-33.

Karl, Polanyi. (2007) The Great transformation: the political and economic origins of our times. In: Trans. ed. Feng Gang, Liu Yang. Zhejiang People's Publishing House.

Li, Jiannong. 2002. The Political History of China, 1840-1928. Fudan University Press, 365.

Liang, Shuming. 1990. The essentials of chinese culture. The complete works of Liang Shuming, Volume III. Shandong People's Publishing House, 145-168. 
Liu, Shaoqi. 1981. Report on the draft constitution of the People's Republic of China, Selected Works of Liu Shaoqi. People's Publishing House, 157.

Qi, Xisheng. 2010. Warlord Politics in China. In: Trans. ed. Yang Yunruo, Xiao Yan. China Renmin University Press, 3.

Robert, Dahl. 1999. On Democracy. In: Trans. ed. Feng Keli. Commercial Press, 9-29.

Sun, Yat-sen. 1996. Three Principles of the People, Selected Works of Sun Yat-sen. Guangdong People's publishing House, 807-927.

Wang, Jian. 2004. A study of the political and geographical structure of the Western Zhou dynasty, Zhongzhou Ancient Books Publishing House, 386-416.

Xiao, Gongquan. 1997. Modern China and a new world: On Kang Youwei's reform and cosmopolitism. Jiangsu People's Publishing House, 193.

Xiong, Yuezhi. 1986. A History of Democratic Ideologies in Modern China. Shanghai People's Publishing House, 99.

Xu, Zhuoyun. 1994. History of Western Zhou. SDX Joint Publishing Company.

Yang, Kuan. 2003. History of the Warring States. Shanghai People's Publishing House, 228.

Zhou, Enlai. 1984. Several Problems related to the CPPCC. Selected Works of Zhou Enlai on the United Front. People's Publishing House, 138-139.

Shangli Lin Ph.D. in political science, vice president, distinguished professor and doctoral supervisor of Fudan University, Changjiang Scholar, a specialist who enjoys the State Council Special Allowance. He has studied in the Chinese University of Hong Kong, Keio University Japan, University of Georgia, and University of Munich as a visiting scholar. His research field mainly covers political theory, comparative politics, and the study of Chinese politics. He has published about 10 books and over 100 papers. His major works include Electoral Politics, The Logic of Politics, Domestic Inter-Governmental Relations, Party Politics and Modernization, The Study of Contemporary Chinese Political Formation, Communitybased Organizations and Neighborhood Building, Party Construction in Communities and the Mass Work, Inner-Party Democracy, Institutional Innovation and National Growth, and so on. 